\title{
El ARCHIVO DE EMPRESA: Archivo Histórico Papelera San Rafael
}

Andrea Silva Barragán*

\section{Resumen}

Este artículo considera la importancia del archivo de empresa como fuente para las investigaciones sobre la historia de aquélla y la de los empresarios. En el texto se exponen algunas de las características contenidas en los acervos empresariales, así como los obstáculos para su preservación y consulta por parte del investigador. Se aborda el caso específico del archivo de una de las empresas productoras de papel más importantes en México, que tuvo su origen en el Porfiriato, y cuyo archivo permaneció por largo tiempo sin orden y en el olvido; sin embargo, en la actualidad constituye una veta importante para la exploración de la historia de la industria papelera, como fue desarrollada varios años por la Papelera San Rafael.

Palabras clave: archivos de empresas, industria del papel, fondos de archivos, historia de empresas.

\section{Abstract}

This paper consider the importance of the company archives as a source for research on the history of that company and business; some of the features contained in corporate collections, as well as obstacles to their preservation and consultation by the researchers are presented. It also describes the specific case of the documentary heritage of one of the most important companies producing paper in Mexico, which originated in the Porfiriato, and whose archive long remained formless and forgotten; however, today is interesting for the exploration of the history of the paper industry developed several years by the San Rafael Company.

* UAM-Iztapalapa. 
Keywords: business archives, paper industry, archival sources, business history.

El archivo empresarial es el conjunto de documentos generados y acogidos en el desarrollo/desenvolvimiento de una empresa desde el inicio de sus funciones mercantiles, en la lógica de producir y comercializar bienes o servicios. Estos acervos documentales permiten contar con testimonios de las acciones y experiencias efectuadas en el desarrollo de sus actividades. La empresa como sujeto histórico, económico y social resguarda una serie de interrelaciones múltiples. Aunque la dimensión de su archivo puede variar (dependiendo del giro, edad o interés comercial), sus documentos son testimonio de la fundación, estructura, desempeño, eficiencia, desenlace y tejido económico, social o político que pudo haber amparado en un periodo histórico. ${ }^{1}$

El archivo de empresa resulta, así, una pieza fundamental para la historia empresarial y de empresas, subdisciplinas de la historia y la economía. ${ }^{2}$

En este sentido, el presente texto parte, en primer lugar, de un acercamiento a la relevancia e importancia del archivo de empresa; en segundo, de mi experiencia en el archivo de la Compañía Papelera de San Rafael y Anexas, para llevar a cabo su rescate y catalogación, lo cual permitió, finalmente, contar con un instrumento de consulta. ${ }^{3}$ Se enumeran, además, las características generales de las secciones y series documentales para ejemplificar la importancia del archivo de una empresa, en este caso, una productora de papel.

1 En este trabajo se utiliza el término "empresarial" para englobar los enfoques en los estudios desde la empresa y el empresario, vistos como parte del mismo engranaje histórico; aunque sabemos que los objetivos e intereses de los dos campos de especialización son diferentes, las fuentes para su estudio pueden ser las contenidas en el archivo de empresa.

2 La historia empresarial se centra en el análisis histórico del desempeño y relevancia del "empresario" (en el clásico sentido schumpeteriano); por su parte, la historia de empresas o business history analiza los cambios en la organización económica de las compañías, que tienen trascendencia con las transformaciones económicas y sociales. Véase Marichal, Carlos, "Avances recientes...", p. 10.

3 El acervo de la Compañía Papelera San Rafael resulta interesante e imprescindible para el conocimiento del desarrollo de la industria papelera en México, al haber sido una de las empresas productoras de papel más importantes desde el Porfiriato y haber mantenido un monopolio en la producción de papel por varias décadas. 


\section{La historia empresarial y el archivo de empresa}

Los primeros estudios académicos relacionados con la historia empresarial (business history) surgieron hacia 1920 en Estados Unidos. En 1927, en la Escuela de Administración de la Universidad de Harvard (Harvard Business School), N. S. Gras comenzó a estudiara las grandes empresas; posteriormente, otros investigadores se interesarían en el análisis de empresarios, como Henry Ford. Existen diversas modalidades de estudio en este reciente campo de especialización: la historia de las empresas (compañías o firmas), o company history, otro es la historia de los empresarios (entrepreneurial history); ambas ramas complementarias, aunque con objetos de estudio diferentes. Dentro de la primera se atiende la evolución de las organizaciones de negocio a partir de su estructura constitutiva, estrategias empleadas y los resultados obtenidos; por su parte, la historia de los empresarios se centra en las personas emprendedoras que han estado presentes en la creación y dirección de las empresas.

Uno de los mayores exponentes de la bussines history es el historiador económico Alfred Chandler.

Chandler pushed historians not to look at business as an abstraction. He wanted us to view change and the evolution of business enterprises, with all their shifting needs and requirements. He documented the courses followed by leading companies as they conducted both their national and their international affairs. He asked us to study the impact of technological change on corporate strategies and to try to understand why some companies expanded into the international sphere while others did not. ${ }^{4}$

Este llamado de atención pronto encontró eco en América Latina. Aquí la intensa intervención del Estado hizo que a partir de los años setenta se

\footnotetext{
4 Wilkins, Mira, "Chandler and global business history", p. 264. El trabajo de Alfred Chandler, La mano visible, es un referente en los estudios de la business history, al centrarse en el análisis del nacimiento y desarrollo de la gran empresa estadounidense, algo que hasta ese momento no se había hecho. Una de las líneas de este trabajo es que a fines del siglo XIX y principios del XX surge en Estados Unidos un nuevo capitalismo donde los gestores ejecutivos y del consejo de administración suplantaron la mano invisible de las fuerzas del mercado.
} 
iniciara la búsqueda de una apertura comercial y una explicación al papel que, hasta ese momento, habían desempeñado las empresas/empresarios a nivel nacional. ${ }^{5}$ Este florecimiento de estudios sin duda coincidió con importantes cambios económicos y políticos en 1980: reformas neoliberales, la inserción de la región en el nuevo ciclo de globalización y el fortalecimiento de los gobiernos democráticos en países como Argentina, Brasil y Chile. ${ }^{6}$

Los primeros estudios en los países latinoamericanos se dieron mayormente en Brasil, Colombia, Argentina y México. Así, desde mediados de los ochenta se observa un ascenso en la cantidad y calidad de las investigaciones emprendidas y en los resultados obtenidos, aunque con diferencias entre cada situación nacional/regional. Este desenvolvimiento de estudios empresariales buscó en los fenómenos económicos alejar la mira de explicaciones generales, para acercarse a interpretaciones que expresaran y emplearan su estructura mediante conclusiones acordes con sus particularidades espaciales. En el caso de México, durante los últimos años las investigaciones en esta disciplina muestran diversidad: en la historia de la banca, la industria, los servicios, el comercio y el transporte. ${ }^{7}$ Encontramos una proliferación en los estudios de empresas y empresarios sobre todo de los siglos XIX y XX.

Este esfuerzo, por parte de la historia empresarial, de buscar nuevas temáticas y objetos de estudio para ofrecer una perspectiva histórica y temporal renovada sobre la vida empresarial, ha hecho que se desemboque en: 1) una comparación de los espacios estudiados, 2) una creación de instancias especializadas en este tema de estudio -como la Asociación

5 En América Latina durante los años sesenta y parte de los setenta prevalecieron algunas caracterizaciones a su economía y sociedad, en las que la influencia de modelos teóricos predictivos y prescriptivos del desarrollo económico no estimularon la investigación empírica del empresariado, marcando un abandono de este campo y espacio de estudio. Véase, Dávila, "La presencia de la historiografía empresarial".

6 Para observar el desarrollo de los estudios empresariales en estos países pueden consultarse, Dávila, Carlos, Los estudios empresariales en Colombia a principios del siglo XXI (con una referencia de México), Dávila y Roy Miller, Business History in Latin America, y para observar el caso mexicano, sin duda, Carlos Marichal y Mario Cerutti, Historia de las grandes empresas en México, han abonado este campo de investigación con sugerentes aportaciones.

7 En el caso de los centros de archivos de empresa fuera de México, en Europa, se ha dado en parte esta diversidad gracias al desarrollo de importantes escuelas de historia económica; su situación se vincula con el modelo económico en el que la misma empresa se ha desenvuelto. Para un balance de la situación de los archivos véase González Pedraza, José Andrés, "Los archivos de empresas". 
Mexicana de Historia Económica y el Comité Mexicano para la Conservación del Patrimonio Industrial-, y 3) un uso y explotación de otras fuentes públicas y privadas; en este caso, el archivo de empresa cobra notoriedad.

Estos espacios académicos y de investigación, ligados al archivo de empresa, iluminan sólidamente las propuestas, preguntas y respuestas que permiten revisar y generar conceptos, métodos y explicaciones sobre esta disciplina.

Así, a partir de los archivos empresariales podemos reconstruir, desde entornos económicos y políticos, el origen, desenvolvimiento e implicaciones sociales y culturales del surgimiento, consolidación o desaparición de una empresa. Sin duda, el archivo de empresa es la fuente para hacer la historia de las empresas (business history).

Los primeros pasos en la conservación de este tipo de archivos se dieron en 1905, en Alemania. Desde entonces encontramos diversos esfuerzos en países como Francia, España, Estados Unidos y Canadá. En México, es hasta finales de los años setenta del siglo XX cuando surge el interés por su conservación. ${ }^{8}$

\section{Archivo de empresa: ¿una fuente sólo para lo empresarial?}

Los estudios empresariales e industriales despliegan una relación con el acceso a archivos privados, tanto de empresas como de empresarios, pues su consulta resulta fructífera al hilvanar el tejido empresarial.

El archivo de empresa puede ser fuente para la historia social, económica, política, tecnología, ecológica y cultural; permite plantear diversas interrogantes como: ¿cuáles fueronlas redes de relación entre sus accionistas y su participación en la empresa?, el crecimiento o declive de cierta industria, ¿qué cambios trajo en la región donde comenzó su desarrollo?, ¿qué elementos permitieron la estructuración de la empresa, y su impacto o relación con el mercado en cierto periodo histórico? Además, podemos inferir la capacidad de respuesta de la empresa frente a problemas en la producción o dirección, sin tener la necesidad de recurrir a cortes abruptos por los tajos de tipo político. Asimismo, se puede observar la influencia de los diferentes cambios institucionales y su efecto negativo o positivo en el desempeño de la negociación.

8 Oviedo Gámez, Belem, “Los archivos industriales en México”, p. 71. 
En el aspecto ecológico, podemos advertir las transformaciones espaciales por la instauración de empresas, las cuales, en la búsqueda de recursos naturales para el uso industrial, provocan descontentos y conflictos con los pobladores. Así, se presentan interrogantes como: ¿cuáles fueron los conflictos entre sociedad y empresa originados por la redistribución de recursos, como el agua que se usa para la producción en diversas industrias?

En los documentos de empresa se hallan, además, las relaciones de los directivos, trabajadores o dueños de la empresa con los actores políticos. Así, podemos cuestionar: ¿cómo fue la relación de la empresa con la élite política?, ¿cuáles fueron los conflictos entre inversionistas y gobierno al tratar de conseguir tarifas especiales en la compra o importación de materias primas o maquinaria? Las respuestas de estas preguntas, contenidas en los documentos de la empresa, pueden matizar aquellos estudios nacionales; y aquí es importante notar la relación de los archivos de empresa con los estudios regionales, que permiten precisar y definir características y rasgos -muchas veces no contemplados- de una empresa en particular.

Esta tendencia de especialización en la historia de la empresa constituye, así, nuevos campos de investigación que revelan un futuro prometedor para la disciplina. Y es precisamente el archivo de empresa uno de los puentes que permite tal riqueza de planteamientos. El acervo empresarial es un campo fértil donde se pueden inferir causas, consecuencias, conclusiones, caracterizaciones y la relación entre empresa y empresarios; además, permite profundizar en aspectos como la competitividad, los cambios derivados de la introducción y la adaptación de nuevas tecnologías, así como observar, al mismo tiempo, su injerencia en los mercados regional y nacional.

Otra contribución más encontrada en este tipo de archivos es su flexibilidad temporal; es decir, podemos mirar periodos que en ciertas ocasiones no es posible estudiar con fuentes tradicionales; como dice Gómez Galvarriato, debido a los abruptos cortes que nos impone la consulta de otro tipo de fuentes: "La continuidad de los archivos empresariales nos permite observar, valorar, analizar y describir los cambios y permanencias que las rupturas políticas pudieron significar y que es difícil, si no imposible, encontrar en otro tipo de fuentes"?

9 Gómez Galvarriato, Aurora, "Sacando la nuez de la cáscara”, p. 26. 
Así, estos depósitos de documentos históricos conforman una apertura prometedora para reelaborar problemas y articular procesos económicos, políticos o sociales. ${ }^{10}$ Estas fuentes nos marcan un camino naciente en lo económico que bien puede desembocar en aspectos culturales y sociales dentro de la historia. ${ }^{11}$

A partir de los archivos empresariales podemos llegar a contar historias de los más diversos temas. Por supuesto son la fuente por excelencia para hacer historia de empresas (business history). En ellos podemos compenetrarnos en la historia del funcionamiento de la empresa, su organización, su forma de financiamiento, de toma de decisiones, su tecnología, su productividad, sus utilidades o pérdidas, la red comercial en la que se insertaba, su relación con sus trabajadores, con el gobierno y con otras empresas. ${ }^{12}$

La empresa y su acervo permiten al investigador establecer una serie de planteamientos útiles para la elaboración y comprobación de nuevas teorías que permitan conocer el funcionamiento y tejido empresarial de alguna industria o empresa. Sin embargo, uno de los obstáculos es la preocupante situación en general del archivo empresarial. "Especialmente grave es el problema planteado por la desaparición de archivos empresariales. La destrucción de un archivo de empresa es algo similar a la eliminación de los archivos en el disco duro de una computadora". ${ }^{13}$

10 Cuando se establecía un enclave industrial muchos de los habitantes de zonas cercanas se insertaban en el trabajo obrero; ello provocaba cambios de hábitos y costumbres no sólo mental, sino materialmente, al incorporar instrumentos y espacios arquitectónicos distintos a los comúnmente usados y conocidos por los pobladores del lugar.

11 En los últimos años, el estudio de la industria y la empresa ha arrojado nuevas propuestas y refutado ciertas generalizaciones; en suma, el uso de fuentes desconocidas puede ejemplificar estos aportes y propuestas de análisis. Aurora Gómez G. ha propuesto, desde su experiencia en el estudio de empresas como Fundidora Monterrey, que la consulta del archivo de empresa le permitió encontrar nuevas conclusiones. Una de las cuales fue que el abastecimiento de materia prima afectó la producción de la fundidora, argumento, por otro lado, diferente al de Stephen Haber. Véanse La nueva historiografía, Industria y subdesarrollo. La industrialización de México 1890-1940, 1992 y Gómez Galvarriato Aurora, "Industrialización, empresas y trabajadores industriales: del Porfiriato a la Revolución”, 2003.

12 Gómez Galvarriato, op. cit., p. 28.

13 Marichal, Carlos, "Introducción”, p. 5. 


\section{Un archivo de papel: el caso San Rafael}

Antes de adentrarse en el archivo de empresa, es necesario conocer el funcionamiento de ésta, para interpretar sus documentos. Si bien las empresas de un mismo periodo histórico o ramo productivo pueden presentar similitudes en su forma de organización, producción y comercialización, no siempre la documentación generada será la misma, tampoco la que puede llegar a nuestras manos. Para entender su forma de administración una de las alternativas es consultar el organigrama, aunque llegados a este punto nos topamos, en la mayoría de los casos, con un archivo que nos niega su consulta.

Los motivos de la falta de acceso al archivo empresarial son diversos y dependen, en principio, de la apertura de sus poseedores o responsables de resguardo. Además, tenemos el inconveniente de la conservación del acervo documental a la cual regularmente se le asigna nula importancia. Así, estos archivos se encuentran en un estado precario y de abandono.

Cuando se ha logrado derribar la muralla que nos separaba del acceso al recinto documental en cuestión, otros problemas acechan nuestro manejo en su interior. Al entrar en el espacio que abriga la documentación, podemos encontrar un archivo que, aunque no contiene toda la información generada por la empresa a lo largo de los años, está al menos limpio y con un orden modesto; o podemos encontrarlo en el abandonado, sin orden y con graves daños en sus documentos. En el caso de la Papelera San Rafael, el archivo estaba entre ambas líneas, pues contaba con un espacio destinado a su almacenamiento, pero desordenado, sucio y sin instrumento de consulta.

Frente a este panorama, un tanto desolador, se comenzó un proyecto de rescate y catalogación cuyo resultado sería el Archivo Histórico Papelera San Rafael (AHPSR). El desarrollo del proyecto se llevó a cabo con la ayuda de la asociación civil Apoyo al Desarrollo de Archivos y Bibliotecas de México (ADABI), desde fines de 2009 y hasta 2011.

El AHPSR contaba con documentación que iba desde escrituras, contratos y correspondencia, hasta diversos libros, en su mayoría de contabilidad, y algunas fotos y negativos.

Antes de comenzar a describir el proceso de su catalogación, brevemente mencionaré parte de la historia de la papelera San Rafael. 
Imagen I. Vista panorámica de la fábrica de Papel San Rafael, c.1920

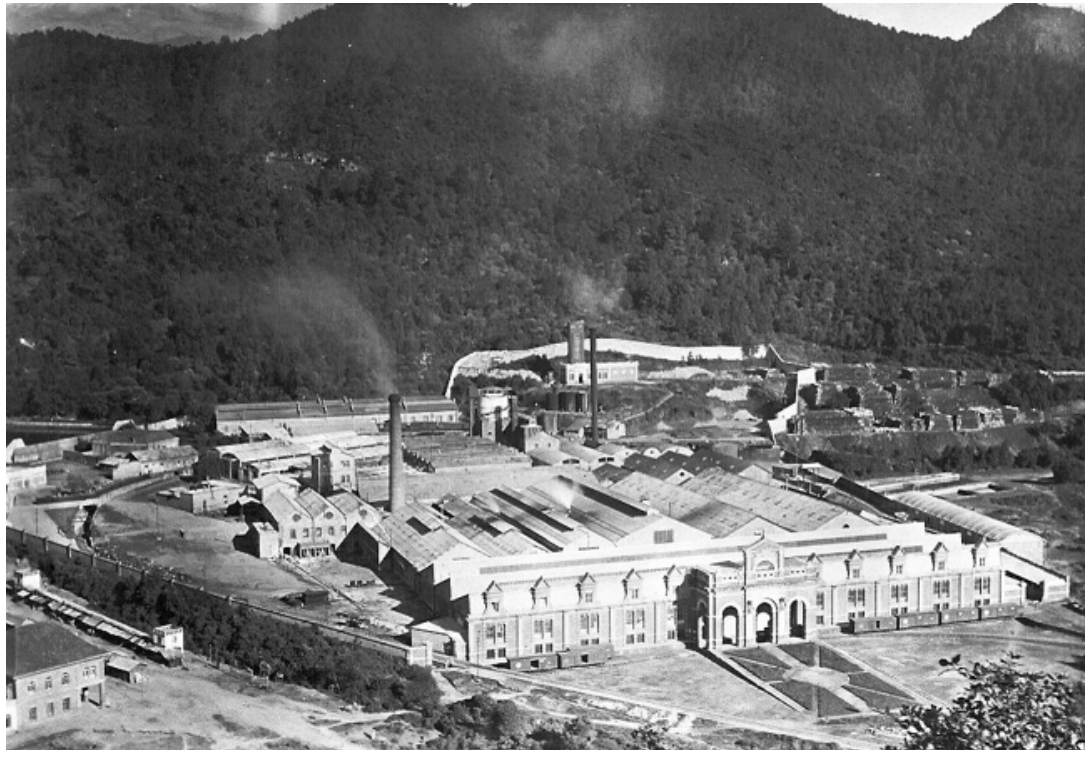

Fuente: AHPSR, Panorámicas.

\section{Breve historia de la Compañía Papelera San Rafael}

La fábrica San Rafael se estableció en el pueblo de San Rafael, perteneciente al municipio de Tlalmanalco, Estado de México, una región rural donde habían prevalecido haciendas y ranchos inmersos en una comunidad dispersa. Las actividades productivas de la región eran la agricultura y algunas manufacturas. ${ }^{14}$

En el último tercio del siglo XIX se difundieron rumores de que se instalaría una fábrica de papel. El 14 de enero de 1889 Andrés Ahedo y José Sánchez Ramos formaron la sociedad colectiva bajo la razón social Ahedo y Compañía, con el objeto de explotar una fábrica de papel en el molino del Socorro. ${ }^{15}$ El señor Andrés Ahedo, de 47 años, se encargaría

14 Junto a la industria papelera existía una fábrica textil llamada Miraflores, fundada en 1838. 15 AHSPR; avalúo 1894, sin clasificar, p. 30. 
de la administración de la fábrica y el molino, José Sánchez Ramos, ${ }^{16}$ de 36 años, atendería los asuntos independientes a la sociedad. El 4 de marzo de 1889, la J. H. Robertson y Cía., vendió a José Sánchez Ramos el terreno de una ferrería llamada San Rafael. ${ }^{17}$

Para 1891 la sociedad Ahedo y Compañía se disolvió por mutuo consentimiento; enseguida José Sánchez Ramos, el 4 de mayo del mismo año, celebró un contrato con Thomas Braniff, bajo la razón social Sánchez Ramos y Compañía, teniendo en posesión el activo y pasivo de los bienes que había adquirido antes con Andrés Ahedo, y dando en pago a éste el molino del Socorro. Constituida la sociedad Sánchez Ramos y Cía., se propusieron terminar las construcciones e instalaciones de la fábrica de papel y echar a andar la negociación. Con motivo de la formación de la papelera, el 19 de marzo de 1890 se colocó la primera piedra y se menciona que dos años después comenzó a despachar sus primeros productos. ${ }^{18}$ Según acta constitutiva de formación, con normas y cláusulas específicas, la sociedad Compañía de las Fábricas de Papel San Rafael y Anexas, Sociedad Anónima ${ }^{19}$ fue constituida formalmente el 28 de julio de 1894, teniendo como únicos accionistas a Thomás Braniff y Sánchez Ramos, ejerciendo ambos las funciones del Consejo de Administración. Posteriormente, el señor Henry Campbell Waters ${ }^{20}$ se unió a esta sociedad adquiriendo 10 acciones. La duración de la sociedad se fijó en 50 años a partir de la firma de escritura de 1891, teniendo su domicilio en la ciudad de México para ventas, reuniones y acuerdos.

La Papelera San Rafael figuró, así, como una industria integrada verticalmente, que innovó el proceso productivo y mantuvo una estrecha

16 Él y su hermano, Delfín Sánchez Ramos, fueron destacados comerciantes e inversionistas emparentados con Benito Juárez.

17 AHPSR; sección Gobierno, serie Escrituras, exp. 6.

18 Compañía de las Fábricas de Papel San Rafael y Anexas, S. A., Homenaje de la Compañia de las Fábricas de Papel de San Rafael y Anexas, S. A., al Congreso Mundial de la Prensa, p. 26.

$19 \mathrm{La}$ sociedad posteriormente absorbería otras fábricas papeleras del país para tratar de controlar el mercado del papel. Al centrarse el presente trabajo sólo en la compañía San Rafael, me refiero a esta negociación como Papelera San Rafael, pues el objetivo es describir su archivo.

20 Tanto Tomas Braniff como Sánchez Ramos, y Henry Campbell Waters eran accionistas de la Negociación Agrícola de Xico, S. A., empresa que se encargaba de la explotación industrialagrícola de las siete haciendas de Chalco propiedad de Íñigo Noriega. 
relación con ingenieros e inversionistas extranjeros, lo que en cierta forma contribuyó a asegurar el éxito empresarial de la compañía.

Con el paso de los años la compañía papelera logró monopolizar el mercado del papel, empleando diversas estrategias administrativas y comerciales; absorbió algunas fábricas de papel mediante la compra de sus instalaciones o pactando algunos contratos restrictivos. En otras maniobras, San Rafael se fusionó para ampliar su producción y, por ende, su presencia en el mercado. Esto fue lo que pasó en 1904 al fusionarse con Progreso Industrial, ubicada en Villa Nicolás Romero; San Rafael se concentraría en papel periódico y Progreso en papeles de escritura finos y couché.

La producción papelera de esta compañía, sin embargo, enfrentaría algunos estragos, derivados de las tensiones políticas y económicas del país, como fue el impacto del movimiento revolucionario de 1910, o cuando en 1936 debió afrontar la creación de la Productora e Importadora de Papel S. A., (PIPSA) por parte del Estado en 1935.

\section{La elaboración del inventario. Archivo Histórico de la Papelera San Rafael}

Las andanzas productivas de papel, así como todas las relaciones comerciales y políticas entretejidas por la compañía papelera, quedaron reflejadas en sus documentos generados día a día. Todo el acervo muestra el andar administrativo de su mismo entorno sociopolítico y económico.

El método de organización documental se sustentó en el principio de procedencia y orden original; esto es, relacionando cada documento, sea un libro, un acta o escritura, con la entidad que lo produjo; para tal fin, es indispensable conocer el contexto en el que se crearon los documentos. Uno de los requisitos para esta tarea era conocer la forma en que trabajaba la empresa, sus dependencias, oficinas y departamentos, retomando al mismo tiempo su historia. Al no contar con un organigrama, las Actas de Consejo fueron una guía para conocer los cargos y, por ende, el funcionamiento de la papelera, además de su estructuración productiva, el funcionamiento de sus departamentos y oficinas.

Una vez creado el cuadro clasificador, se trasladaron los documentos del archivo histórico a un lugar amplio y limpio donde se iniciaría la limpieza 
de los libros y documentos con brochas de pelo suave. Posteriormente, se separaron los documentos por secciones y se ordenaron cronológicamente. Una vez obtenidas las secciones, se formaron las series, de acuerdo con nuestro cuadro clasificador. Ordenados los documentos en secciones y series, se continuó con los expedientes o legajos, se les hicieron, con papel cultural, las guardas de primer nivel. A cada expediente se le puso al frente una hoja con los datos: nombre del archivo, sección, serie y número de expediente; además, estos datos están anotados en cada esquina superior de las guardas para tener un mayor control de los expedientes.

Las secciones y series documentales reflejan las funciones de la compañía papelera. Así, se obtuvieron finalmente dos secciones. ${ }^{21}$ La primera, titulada

\section{IMAgEN II. ANTES DEL PROCESO DE RESCATE DEL ARChIVo PAPELERo SAN}

\section{RAFAEL.}

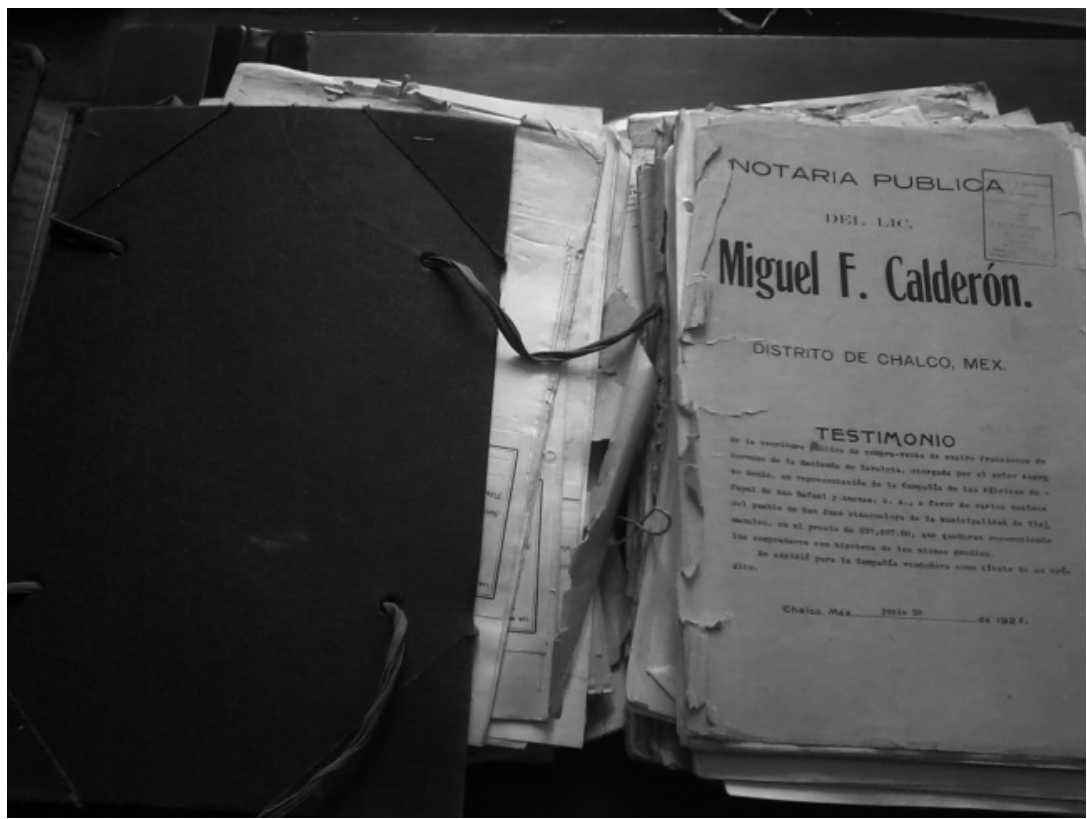

Fuente: Colección particular.

21 La clasificación final de la documentación del archivo, de la razón de sus secciones y acomodo, fue posible gracias a la ayuda de ADABI, en especial del profesor Jorge Garibay Álvarez, quien me alentó y guió en esta tarea de rescate. 
Gobierno, contiene la información de la administración de la empresa, es decir, sus Asambleas, Actas, Estatutos, Acciones, Jurídico, Asuntos de Aguas, Correspondencia y Hemeroteca, las cuales conformaron las series documentales. Esta sección cuenta con un total de 8 cajas, que abarcan 140 expedientes, y un periodo de 1911 hasta 1960.

La segunda sección es Contabilidad; contiene la parte contable y sus series son: Ventas, Producción, Inventarios, Contratos, Escrituras, Permutas, Correspondencia, Anexos y Hemeroteca. Esta sección quedó resguardada en un total de 8 anaqueles donde se colocaron los libros, que por sus características físicas no podían ser alojados en cajas. Por su parte, las series de Contratos, Escrituras, Permutas, Correspondencia y Anexos se resguardaron en un total de 5 cajas. El periodo comprendido por esta sección es de 1893 a 1962.

El archivo finalmente se nombró Archivo Histórico Papelera San Rafael (AHPSR); contiene información desde 1890 hasta finales del siglo xx; sin embargo, se hizo un corte temporal en la clasificación del acervo hasta los años cincuenta del siglo Xx.

\section{Documentación AHPSR}

La mezcolanza documental del archivo papelero expone el desenvolvimiento de sus actividades, pues la empresa al comprar, producir, vender, arrendar, traspasar y comerciar, registró minuciosamente cada movimiento. Este acervo se refiere también a otra empresa papelera: El Progreso Industrial, lo cual resulta atractivo, pues la misma escasez de archivos de empresas -aún más del sector papelero- hace que el AHPSR cobre notoriedad para conocer cómo se comportó la producción y el mercado de papel en México de fines del siglo XIX a principios del Xx. ${ }^{22}$

22 "La papelera San Rafael se fusionó con Progreso Industrial, y la información producida por Progreso se perdió, pues no se cuenta con ningún archivo. Las únicas fuentes disponibles se encuentran en el Archivo Municipal de Villa Nicolás Romero, donde se encontraba esta fábrica; por ello, la historia de la misma podría complementarse o intentar reconstruirse con las mínimas referencias que el Archivo San Rafael posee en su documentación”. Silva, El desarrollo industrial de una fábrica de papel: La compañia papelera San Rafael y Anexas S. A. (18941919), p. 153. 
IMAGEN III. CUADRO DE CLASIFICACIÓN DEL AHPSR.

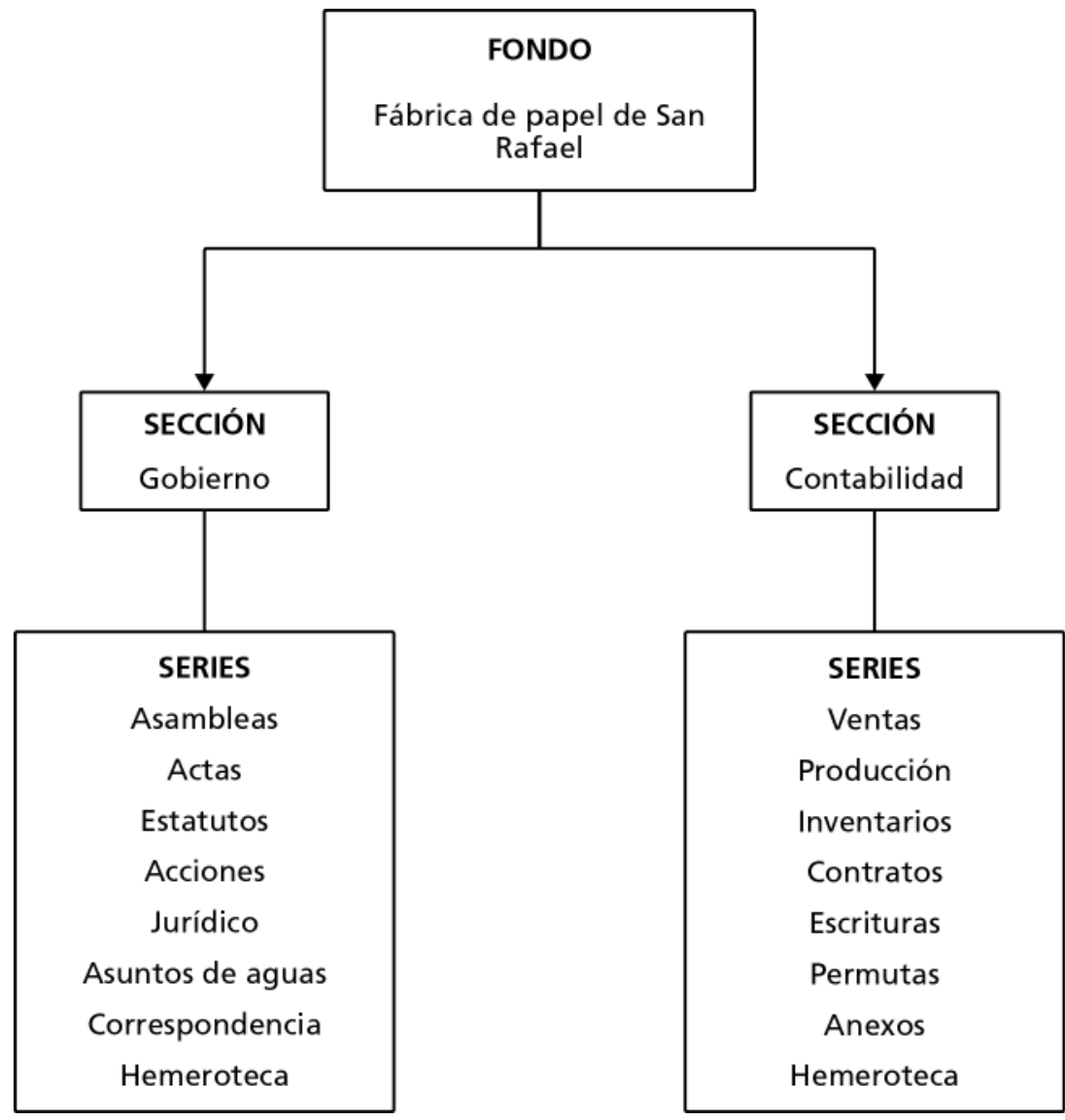

El cuadro clasificador consta de dos secciones: Gobierno se refiere a la información cualitativa; Contabilidad a la cuantitativa. Enseguida se exponen algunas diferencias y particularidades de ambas secciones.

\section{a) Sección Gobierno}

Entre los múltiples tipos de documentos -y los más básicos para conocer una empresa- se pueden encontrar sus registros de la Asamblea General de Accionistas, que son informes sobre los pormenores y acuerdos de 
la empresa durante un año de actividades. El análisis de las asambleas permite establecer la relación de los empresarios participantes, los cargos y nombramientos dentro de la negociación; además, hacen posible observar las pérdidas, ganancias y el balance general, algunas gráficas ejemplifican las finanzas anuales. En suma, la información de estos documentos ayuda a reconstruir las estrategias comerciales, los problemas de abastecimiento de materias primas, los acuerdos con casas comerciales, la compra de maquinaria, el aumento de capital y la historia del comercio y producción papelera de la época. En el AHPSR están registradas las asambleas desde 1911 hasta 1952.

En las reuniones de las asambleas generalmente se comenzaba redactando la fecha, hora y lugar de la reunión; posteriormente, se proseguía con la orden del día, dando lectura siempre en primera instancia al acta de la reunión anterior para decidir su aprobación; después se trataban los asuntos previamente anunciados y conocidos por los miembros de la junta. ${ }^{23}$ Por ejemplo, en el acta de 1911, después del orden del día y acta anterior, se pasó a la aprobación de aumento de capital acordado y a la elección de la junta directiva, nombrando a los nuevos accionistas y empleados. Estos datos permiten seguir la distribución de cargos y, en varias ocasiones, los salarios percibidos, así como las inconformidades por restitución de algún accionista.

Por su parte, las Actas del Consejo de Administración permiten seguir de cerca las estrategias y organización internas de la empresa, las decisiones, propuestas y problemáticas enfrentadas por los miembros que formaron parte del Consejo de Administración. Estas actas van de 1898 a 1967 y detallan las decisiones sobre la administración de la papelera.

Enseguida tenemos la serie Estatutos, de 1879-1972, que da cuenta de los cambios de nombre o aumentos de capital por los que atravesó la empresa; después tenemos los títulos de Acciones, desde 1906 hasta 1956. Los documentos de Jurídico ejemplifican los problemas con terceros debidos a propiedades o inconvenientes comerciales o productivos, desde 1856 a 1967. En la serie Asuntos de Aguas se revelan múltiples y extensos conflictos por el uso y aprovechamiento de este recurso, debido a la

23 Las fechas y asuntos tratados en las juntas de las asambleas generales eran previamente anunciadas en periódicos o publicaciones de circulación nacional, como el Boletín Financiero y Minero de México. 
necesidad de proveerlo para las actividades productivas, desde 1895 a 1962. Por su parte, Correspondencia abarca desde 1929 hasta 1939 y da cuenta de diversas relaciones entre la compañía y compradores, proveedores o relaciones con diversos actores políticos y sociales.

\section{b) Sección Contabilidad}

La contabilidad es parte fundamental de toda empresa, pues numéricamente muestra el comportamiento de la misma. Los libros de contabilidad eran usados, según costumbre del siglo XIX, por el método de partida doble; es decir, las cuentas se registraban en dos columnas en relación con un Debe (activo) y un Haber (pasivo). Según el Código de Comercio de la época -1889- se obligaba a comerciantes o empresarios a llevar la contabilidad en tres libros esenciales: Diario, Mayor e Inventarios.

En la sección Contabilidad del archivo papelero, encontramos la serie Ventas, desde 1893 a 1955; se compone de libros que llevaban la contabilidad y registro de todas las actividades dentro y fuera de la empresa, pudiendo hacer con ello una reconstrucción del desarrollo de la actividad papelera en San Rafael. En esta serie encontramos libros de cuentas, de mayor, de diario, deudores y acreedores, ventas, de caja, ingresos y egresos. Con estos materiales se puede hacer un acercamiento a sus cuentas y entender cómo se conformó y comportó la producción y venta de papel.

La serie Producción inicia en 1928 y termina en 1951. Aquí podemos encontrar muestrarios del papel que producía la fábrica, los tipos y precios, así como el gramaje en que se vendía. La siguiente serie es Inventarios, va de 1900 a 1978 y nos acerca a los cambios en la producción del papel, pues ilustra los costos, tipos y, a veces, las características de las máquinas y demás mobiliario traído a la planta de San Rafael.

En el caso de los Contratos, los más antiguos son de 1890. En ellos se detallan los costos de terrenos y propiedades que se incorporaron a la negociación, siendo los más recientes de $1962 .{ }^{24}$ Por su parte, Escrituras

24 Destaca una colección de más de 200 contratos de terrenos en Morelos en 1890, los cuales años después, San Rafael adquiriría por medio de su representante para incorporarlos en la explotación de materia prima, madera, para la producción de papel. A partir de los contratos y escrituras se pueden conocer y entender los escenarios cambiantes de la propiedad legal de la tierra, y su incorporación al proceso productivo del papel. 
incluye títulos de propiedad que adquirió la empresa desde 1879 hasta 1943; estos expedientes permiten seguir la historia de las adquisiciones e inversiones en bienes inmuebles, aportando datos cuantificables y descriptivos.

La siguiente serie, Permutas, se refiere a intercambios de propiedades o créditos desde 1923 hasta 1967. En Correspondencia se encuentran registros desde 1901, los cuales son recibos de pago, algunos telegramas y cartas, las últimas de 1959. Anexos contiene algunos mapas que no correspondían a ningún expediente.

Finalmente, la Hemeroteca posee una colección especial del Boletín Financiero y Minero de México, desde la década de los veinte del siglo XIx hasta los años cincuenta del siglo xx. Este boletín era una publicación emitida periódicamente que anunciaba las reuniones de diversas compañías, así como cotizaciones o venta de acciones. ${ }^{25}$

Como ejemplo de la relevancia de la documentación del AHPSR mencionaré las características del libro de Diario y su valor como fuente de estudio. En él se anotaban los registros y ejemplificaban todas las cuentas generadas día a día; desde cuánto se pagaba por enseres hasta lo que salía de la planta, todo permanecía asentado en el libro. Estos datos se complementan con los libros de Mayor, que contenían un registro de las cuentas en forma clasificada, y de Caja, que, como su nombre lo indica, registraban todas las cuentas que pasaban por ésta. De hecho, las cuentas del libro de Diario se transcribían al libro de Mayor, lo que en cierta forma implicaba un doble trabajo y un riesgo al realizar alguna omisión o alteración.

En síntesis, el libro de Diario es numéricamente el desarrollo histórico de la papelera, pues muestra las operaciones diarias. "Son dos las formas fundamentales del libro Diario: la primera a dos columnas, al que se llamaba

25 Además, sus páginas contienen una serie de anuncios de diversas empresas y productos, que bajo un análisis detallado pueden ofrecer un acercamiento a las estrategias de las empresas en el comercio de sus productos, los precios establecidos y el origen de varias empresas, pues muchos anuncios se enmarcan bajo un "Since 1890", lo cual indica desde cuando se comenzó a vender o producir algún producto. El Boletín Financiero y Minero de México fue de los primeros libros especializados en temáticas económicas. Esta colección ilustra el nivel de especialización que estaba alcanzando la prensa económica de fines del siglo XIX y principios del xx. A pesar del interés sobre la historia de la empresa en los estudios de América Latina, se han hecho pocos trabajos sobre el origen y evolución de la prensa económica. Véase Pineda Soto, Adriana (coord.), Plumas y tintas de la prensa mexicana, 2008. 


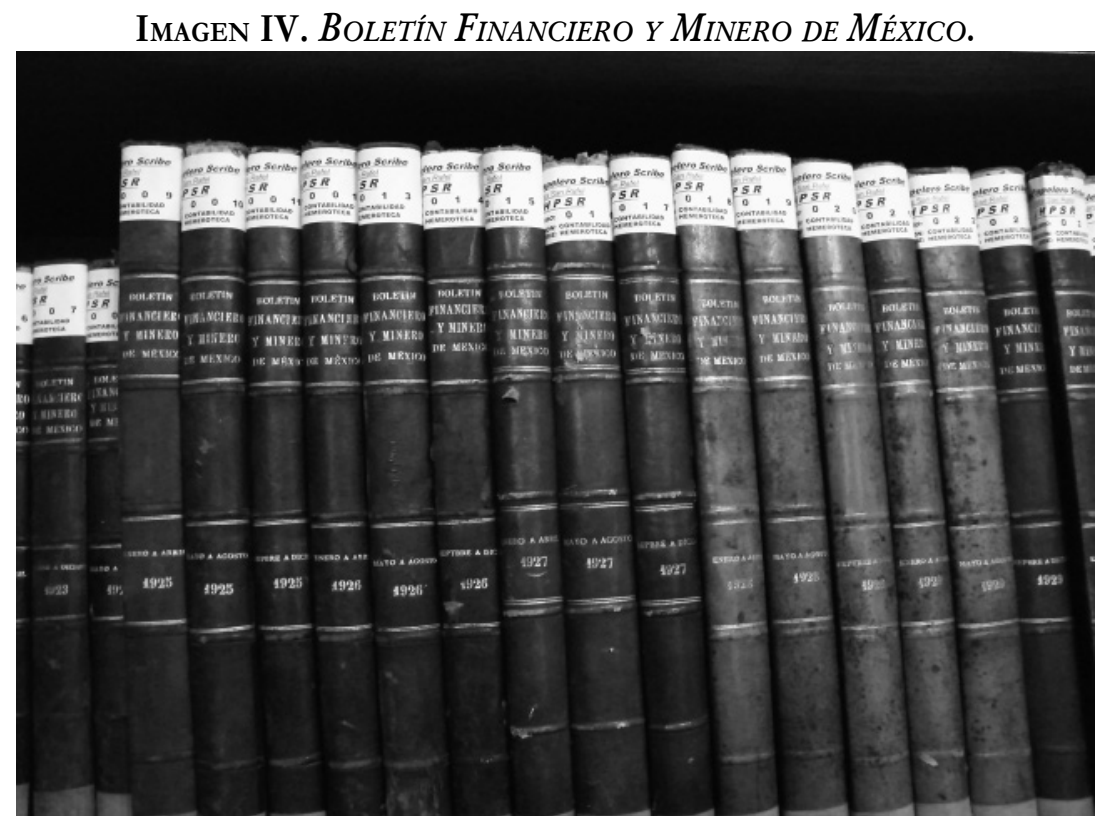

Fuente: Colección particular.

Diario continental, y la segunda a múltiples columnas, llamado Diario tabular". ${ }^{26}$ La papelera San Rafael usó el segundo tipo, y los asientos (es decir, las anotaciones y registros) que van desde la producción de papel, y pasta de madera, hasta ventas, aumentos de capital, pérdidas, compras de diversos enseres y materiales, sueldos, comisiones, existencias en almacén, fletes, cuentas de bancos, gastos especiales, útiles y herramientas, deudores diversos, edificios y construcciones, entre muchas otras referencias.

\section{Consideraciones finales}

El AHPSR es muestrario de una parte de la historia industrial y empresarial del México de fines del siglo XIX y principios del Xx, pues enmarca diversas facetas del desarrollo de la región: sus ocupaciones, relaciones laborales, diversiones y ocio, bosques y agua, problemáticas y arreglos, crecimiento,

26 Castellanos Arenas, Castellanos Arenas, Mariano, "Memoria industrial. El archivo de la Compañía Industrial de Atlixco S. A.”, p. 96. 


\section{IMAGEN V. EsTANTES CON LOS LIBROS DE LA SECCIÓN CONTABILIDAD.}

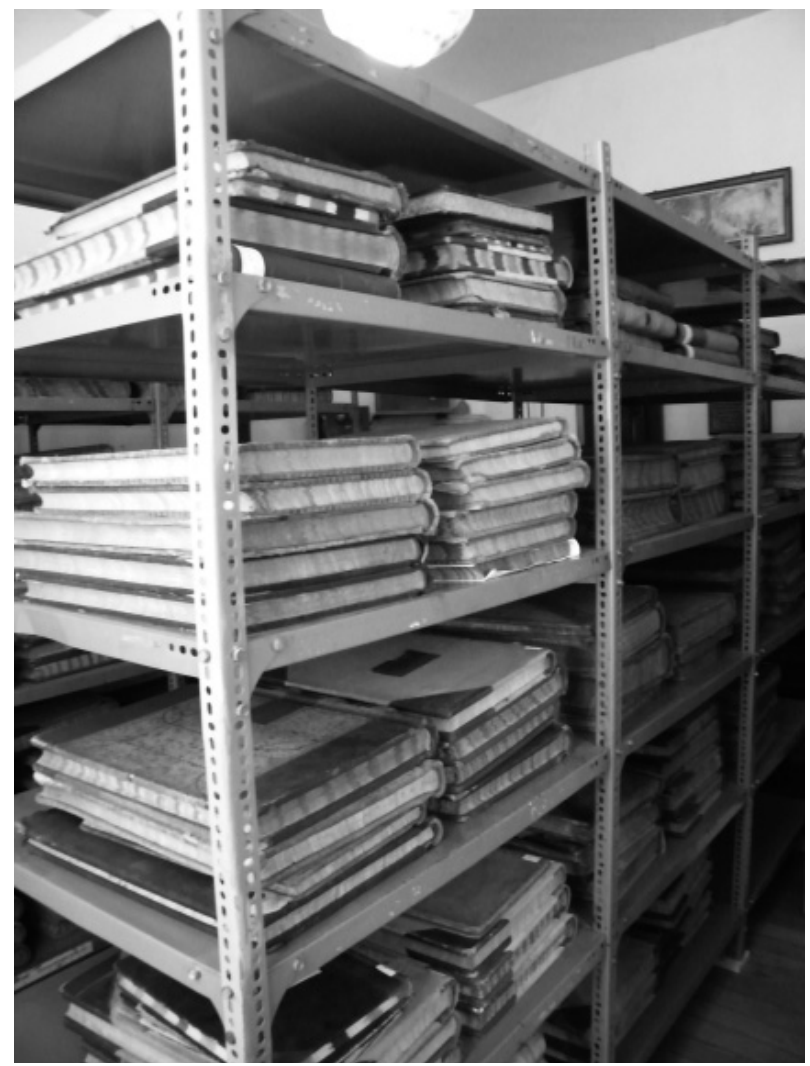

Fuente: Colección particular.

desenvolvimiento como centro fabril, y posteriores cambios en el interior y exterior de sus muros vigilantes del oficio papelero.

El acervo documental de este archivo es huella esencial de sus múltiples historias, las cuales se revelan en sus documentos, que a la vez pueden complementarse con otras fuentes como las notariales o archivos regionales, siempre bajo un análisis interdisciplinario.

El archivo de empresa enriquece la proliferación de nuevos trabajos sobre empresas y grupos empresariales, desde distintos enfoques: económico, tecnológico, social, político y cultural. Actualmente, el interés del investigador ha multiplicado el objeto y las fuentes de investigación para este campo de estudio; así, la compleja realidad empresarial de México se ha 
matizado a partir de los documentos generados por la empresa. De ahí que este tipo de archivo adquiera relevancia, pero al mismo tiempo requiera una reflexión teórica y metodológica por parte del investigador para su abordaje.

Los documentos de una empresa permiten hallar procesos de corta y larga duración, con los cuales es posible conocer los procesos de desarrollo, permanencia o decadencia de muchas empresas. Deviene así un anhelado esfuerzo por rescatar el archivo empresarial, donde las indagaciones e investigaciones, en este campo de estudio, sean guiadas por un método, sustentadas en fuentes confiables y apoyadas por herramientas teóricas cuya eficacia esté comprobada en otros espacios.

Resulta urgente salvaguardar la memoria de cada empresa, pues por pequeña o grande que sea, adentrarnos en su historia permite reconstruir, a partir de su acervo, parte del tejido empresarial mexicano. Este archivo, finalmente, es testigo del fructífero pasado de un producto muy utilizado por la sociedad mexicana de ayer, pero que sigue presente hasta nuestros días. A pesar de la relevancia del acervo, la consulta del archivo no está permitida, al ser parte aún de una empresa privada.

\section{Siglas}

AHPSR (Archivo Histórico Papelera San Rafael).

\section{Bibliografía}

Barbero María Inés, "Business History in Latin America: A Historiographical Perspective", en Business History Review, vol. 82, 2008, pp. 555-575.

Compañía de las Fábricas de Papel San Rafael y Anexas, S. A., Homenaje de la Compañia de las Fábricas de Papel de San Rafael y Anexas, S. A., al Congreso Mundial de la Prensa, México, imprenta de Manuel León Sánchez, 1931.

Castellanos Arenas, Mariano, "Memoria industrial. El archivo de la Compañía Industrial de Atlixco S. A.", en Rescate y conservación del patrimonio industrial, 2008, pp. 85-102.

Dávila, Carlos, "La presencia de la historiografía empresarial en América Latina en los Journals internacionales (2000-2004). Balance, temáticas y perspectivas", en Jorge Basave et al., Los estudios de empresarios y empresas. Una perspectiva internacional, pp. 39-69. 
, Los estudios empresariales en Colombia a principios del siglo XXI (con una referencia a México), Santa Marta, Editorial Unimagdalena, 2013.

Dávila, Carlos y Roy Miller, Business History in Latin America. The experience of seven countries, Liverpool University Press, 1999.

Gómez Galvarriato, F. Aurora, "Sacando la nuez de la cáscara", en América Latina en la Historia Económica, núm. 23, 2005, pp. 25-34.

"Industrialización, empresas y trabajadores industriales: del Porfiriato a la Revolución. La nueva historiografía", en Historia Mexicana, año/vol. LII, núm. 003, 2003, pp. 805-829.

González Pedraza, José Andrés, "Los archivos de empresas: Un estudio comparativo", en Revista Andaluza de Archivos, núm. 2, enero 2010, pp. 31-57.

Haber, Stephen, Industria y subdesarrollo. La industrialización de México 18901940, México, Alianza Editorial, 1992.

Marichal, Carlos y Mario Cerutti (comps.), Historia de las grandes empresas en México, 1850-1930, México, FCE, 1997.

, Marichal, Carlos, "Avances recientes en la historia de las grandes empresas y su importancia en la historia económica de México, en Marichal, Carlos y Mario Cerutti (comps.), Historia de las grandes empresas en México, 1850-1930, México, FCE, 1997.

Marichal, Carlos "Introducción”, en América Latina en la bistoria económica, núm. 23, enero-junio de 2005, pp. 5-10.

Oviedo Gámez, Belem "Los archivos industriales en México”, en Rescate y conservación del patrimonio industrial, 2008, pp. 69-75.

Pineda Soto, Adriana (coord.), Plumas y tintas de la prensa mexicana, México, UNAM, 2008.

Silva Barragán, Andrea, "El desarrollo industrial de una fábrica de papel: La compañía papelera San Rafael y Anexas S. A. (1894-1919)”, tesis de maestría en Historia, UAM I, 2013.

Wilkins, Mira, "Chandler and Global Business History", en Business History Review, vol. 82, 2008, pp. 251-266. 